\title{
Use of Hygroscopic Responsive Wood Prototype for Teaching Performative Architecture
}

\section{SIGRADI2018 TECHNOPOLITICAS \\ xxii congresso da sociedade iberoamericana de gráfica digital 22th conference of the iberoamerican society of digital graphics 07|08|09|novembro|2018 iau usp | são carlos | sp br}

\author{
Gladys Ilka Klein Taparello \\ Universidade Federal de Santa Catarina | Brazil | gladystaparello@gmail.com \\ Patrícia Turazzi Luciano \\ Universidade Federal de Santa Catarina | Brazil | patriciaturazzi@gmail.com \\ Carlos Eduardo Verzola Vaz \\ Universidade Federal de Santa Catarina | Brazil
}

\begin{abstract}
This research presents a method for teaching performative architecture notions to undergraduate students through a practical approach with low cost hygroscopic responsive bilayer prototypes made of wood veneer and aluminum foil. The research occurred in two phases, the first focusing on studying and testing the properties of responsive materials based on wood, and the second, the development and application of two workshops about performative architecture and responsive materials with undergraduate students of an architecture course. This paper shows the results of the workshops, which achieved their goals of stimulating the students and passing knowledge about innovative technologies in architecture.
\end{abstract}

Keywords: Performative architecture; Smart material; Teaching; Wood hygroexpansion.

\section{INTRODUÇÃO}

Esta pesquisa tem como objetivo desenvolver métodos para o ensino de conceitos de arquitetura performativa para estudantes nos ateliês de projeto, utilizando como ferramenta protótipos de madeira higroscopicamente responsivos. No trabalho, foi desenvolvido um sistema de baixo custo para testes de amostras de elementos responsivos de madeira que possa ser facilmente replicado, de modo que os estudantes possam aprender de forma prática noções de arquitetura responsiva.

Os conceitos de limites espaciais e físicos, na arquitetura, podem ser repensados pela perspectiva de limites da termodinâmica, menos rígidos e definidos, funcionando como zonas de troca de energia (Addington \& Schodek, 2005). Nesse contexto, surge a noção de arquitetura performativa, sempre em mudança segundo as alterações do ambiente ao seu redor (Lenz \& Celani, 2015). Os smart materials são desenvolvidos para atender a essa demanda, incorporando mecanismos eletromecânicos que interpretam variáveis ambientais e respondem segundo os dados recebidos (Addington \& Schodek, 2005). Uma das formas já pesquisadas pelos autores Holstov, Bridgens e Farmer (2015) e Reichert, Menges e Correa (2015) é a utilização da madeira em componente higroscópico como envoltório de fachada. A madeira é um material anisotrópico com propriedades higroscópicas que podem ser estudadas para que esse também seja considerado um material responsivo, de menor custo e renovável (Hensel, 2011).
A pesquisa envolveu duas etapas, a primeira de experimentos com madeira como material responsivo, e a segunda, a realização de duas oficinas com alunos da graduação de arquitetura e urbanismo sobre arquitetura performativa e materiais responsivos. Na primeira etapa, foram selecionadas diversas espécies de madeira, que posteriormente foram testadas, com o objetivo de identificar a espécie com a melhor resposta - maior deformação, em menor tempo, com menor tempo de retorno ao formato original - com a variação de umidade. Para os testes, foram confeccionados diferentes protótipos de dupla camada de madeira e construído um ambiente controlado (caixa vedada) com um sistema de liberação de vapor d'água, a partir do qual foram coletados dados ambientais, por meio de um sensor de umidade e temperatura conectado a uma placa Arduino e a um computador, para registro dos dados. Os materiais higroscopicamente responsivos de dupla camada apresentam melhor desempenho quando a camada passiva não apresenta resposta à variação de umidade. Dessa forma, os protótipos da próxima fase de testes foram confeccionados combinando madeira com alumínio, sendo a madeira a camada ativa, e o alumínio a camada passiva, repetindo então os testes dentro do ambiente controlado, com o constante objetivo de identificar a espécie que tem a melhor resposta. A confecção dos protótipos também teve a finalidade de verificar as dificuldades práticas de produção dos componentes. A próxima etapa foi a elaboração, aplicação e avaliação de uma oficina com alunos da graduação de arquitetura e urbanismo, com a finalidade de introduzir os conceitos de arquitetura performativa e materiais responsivos. 


\section{ARQUITETURA PERFORMATIVA E MATERIAIS RESPONSIVOS}

A definição tradicional de limites espaciais na arquitetura está vinculada ao pressuposto de que os espaços são definidos pelos planos compostos pelos materiais, estes estáticos e imutáveis ao longo do tempo de uso da edificação, com pouca ou nenhuma interação com o meio ambiente no qual está inserido e suas variáveis, como temperatura, umidade, luminosidade, variação sonora, etc. (Addington \& Schodek, 2005). Essa visão transforma os limites espaciais em barreiras entre os ambientes externos e internos, criando espaços isolados, tanto em questões de conforto ambiental, quanto em questões de relações sociais, por não proporcionar situações de encontro e interações entre as pessoas (Hensel, 2011).

Uma abordagem mais contemporânea, proposta por Addington e Schodek (2005), embasada nos conceitos de zonas de troca de energia da termodinâmica, encara os limites como sendo áreas de transição entre dois estados, não como um objeto físico definido. Nesse novo paradigma, surge a arquitetura performativa, com seus múltiplos significados, que envolvem desde a busca por otimização de desempenho até interações sociais promovidas por intervenções artísticas, e se torna mais fluída e dinâmica, transformando-se com a passagem do tempo e com variações ambientais (Kolarevic, 2005).

De acordo com Lenz e Celani (2015), em relação à dinâmica da edificação na busca pelo desempenho, a arquitetura performativa pode ser classificada como estática ou dinâmica. Uma arquitetura performativa estática tem seu foco em melhorar o desempenho de algum aspecto construtivo (desempenho térmico, lumínico, estrutural, entre outros) dentro dos conceitos arquitetônicos vigentes sobre as relações de espaço e materiais. Por sua vez, uma arquitetura performativa dinâmica também tem como objetivo a melhoria de desempenho, mas através das definições mais inovadores, que investigam novas formas de abordar os espaços, os materiais e os usuários. Kolarevic (2005) afirma, sobre a dinâmica na arquitetura performativa, que essa pode ocorrer de modo determinado, quando há um planejamento anterior e os movimentos são préprogramados, ou pode ser indeterminado, acontecendo de forma a responder a mudanças no ambiente. A arquitetura contemporânea, com seu foco em performance, tem procurado compreender as relações dos materiais de novas maneiras, concentrando-se mais no comportamento dos materiais e como respondem a variações de estímulos do que somente em suas propriedades físico-mecânicas (Addington \& Schodek, 2005), de modo que a escolha dos materiais e a concepção formal do objeto arquitetônico estejam interligados desde o início do processo de projeto (Kolarevic, 2005). A pesquisa sobre os smart materials, ou materiais responsivos, fornece subsídios para essa área, ao estudar as relações entre as variações de estímulos e a composição dos materiais e seu comportamento de acordo com tais variações (Addington \& Schodek, 2005).

Em se tratando de materiais responsivos, falta um consenso sobre a estrutura geral destes materiais, uma vez que podem ser desde uma estrutura molecular até um conjunto de sistemas. Addington e Schodek (2005) citam as principais características presentes em materiais responsivos:

a. Resposta imediata: que ocorre assim que há a variação do estímulo;

b. Transitoriedade: quando há resposta para mais de um estado ambiental;

c. Auto atuação: por não haver necessidade de mecanismos externos ao sistema para ativação da resposta;

d. Seletividade: quando a resposta é única e previsível para determinado estímulo;

e. Exatidão: quando a resposta ocorre no local onde ocorreu o efeito ativador.

Com base nas propriedades listadas acima, Hensel (2011) propõe o uso de materiais comuns, abordados por um novo viés, que explora as propriedades físicomecânicas e seus comportamentos de modo a obter um melhor aproveitamento do material, e não mais encarando como defeitos o que são respostas a variações ambientais, como as deformações que ocorrem com a madeira conforme as alterações de umidade relativa do ar.

\section{MADEIRA COMO MATERIAL RESPONSIVO}

Os primeiros estudos de Hensel (2011) visavam analisar o comportamento de placas compostas de lâminas de faia coladas em número par com orientações de fibra entrecruzadas, depois de submetidas à mudança de umidade. Descobriu-se que, alternando a posição das fibras entre as camadas, as curvaturas das placas variavam depois de expostas ao aumento de umidade.

Reichert et al. (2015) aprofundaram os estudos sobre madeira como material responsivo, conduzindo testes com amostras com uma camada higroscopicamente ativa de madeira e uma camada passiva de material sintético feito de resina. As principais conclusões sobre os fatores que influenciam na resposta das amostras foram a orientação das fibras da madeira, uma vez que a curvatura das amostras ocorre no sentido perpendicular em relação às fibras; o formato das peças, que se curvam mais conforme forem mais alongadas; e o controle das variáveis ambientais durante a fabricação das amostras, ao permitir a pré-programação dessas, e assim alterar a curvatura resultante. A descrição do controle das variáveis ambientais dos testes inspirou a elaboração do sistema do ambiente controlado utilizado na oficina. Entre os resultados da pesquisa de Reichert et al. (2015) estão dois protótipos arquitetônicos: HygroSkin e HygroScope (Figura 1). 

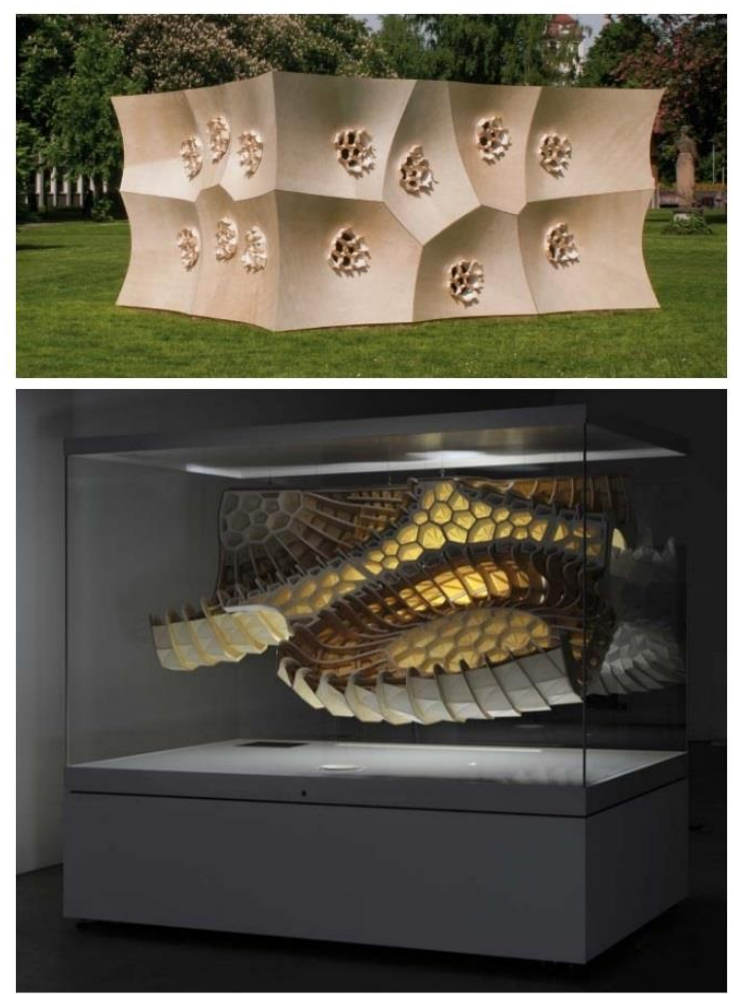

Figura 2: Acima, Hygroskin; abaixo, Hygroscope. Protótipos arquitetônicos produzidos pelo Institute for Computational Design and Construction (ICD), de Stuttgart, Alemanha. Fonte: Menges (2015).

Holstov et al. (2015) também conduziram estudos sobre materiais higroscopicamente responsivos compostos por uma camada ativa de madeira e uma camada passiva de material sintético. A relação entre as espessuras das camadas e a rigidez dos materiais foi uma importante contribuição de Holstov et al. (2015), pois facilita a escolha dos materiais para a elaboração dos protótipos: quando o material de uma das camadas for mais rígido, a outra camada deverá ter maior espessura, para que se possa obter melhor resposta. A seleção de espécies de madeira com maior rigidez associadas a materiais rígidos em camadas passivas mais finas favorece a resposta dos componentes.

\section{MADEIRA E HIGROSCOPIA}

A madeira, quando verde, possui água em estado líquido e vapor em todos os seus poros e cavidades. Essa água pode ser classificada em dois tipos: água livre - que preenche as cavidades - e água de ligação - que está nas fibras celulares. O teor de umidade da madeira é a quantidade de água que existe numa amostra, e pode ser medido de diversas formas, a mais comum é por meio da secagem em estufa (Skaar, 1988). Considera-se a madeira como seca quando seu teor de umidade está entre $20 \%$ e $30 \%$, o que significa que este é o valor correspondente de peso de água em relação ao peso total da amostra. A água presente na madeira seca é a água de ligação, e os poros e cavidades da madeira estão vazios. A importância da diferenciação das águas na madeira vem do fato de que somente a partir do ponto em que as fibras não estão mais saturadas, ou seja, quando começam a perder água de ligação e diminuir o teor de umidade abaixo dos $30 \%$, é que ocorrem as transformações nas dimensões da madeira (Walker, 2006).

\section{METODOLOGIA}

A pesquisa desenvolveu-se em duas etapas, a primeira sendo um estudo teórico e experimental sobre o funcionamento de materiais higroscopicamente responsivos de dupla camada de madeira, e a segunda, oficinas como estudo de caso, com duas turmas da graduação de Arquitetura e Urbanismo, sobre Arquitetura Performativa e Materiais Responsivos (Richardson \& Peres, 1999).

\section{ETAPA 1 - EXPERIMENTOS COM MADEIRA COMO MATERIAL RESPONSIVO EM COMPONENTES DE DUPLA CAMADA}

A seleção de espécies de madeira ocorreu por meio da disponibilidade comercial local de lâminas de espécies listadas no Catálogo de Madeiras Brasileiras para a Construção Civil (Nahuz, 2013), uma vez que esse catálogo apresenta espécies com manejo controlado, diminuindo o impacto ambiental. Foram feitas 21 amostras, de $4 \mathrm{~cm}$ por $12 \mathrm{~cm}$, com dupla camada de madeira, unidas com cola de contato, e orientação das fibras paralelas à menor dimensão das peças, com variação das espécies - angelim pedra, cumaru, curupixá, garapeira, muiracatiara e tauari - para avaliar e identificar as que apresentavam melhor resposta: maior curvatura, em menor tempo, com menor tempo de retorno ao seu formato original. Os testes iniciais foram feitos com as duas camadas em madeira para melhor compreender o comportamento do material, mas assim como Holstov et al. (2015), optou-se por trabalhar com material sintético na camada passiva, para evitar a dupla curvatura que resultaria em esforços internos excessivos na madeira. O material sintético escolhido foi um alumínio usado em estúdios fotográficos, por ser fácil de trabalhar manualmente e pela disponibilidade (Figura 2).
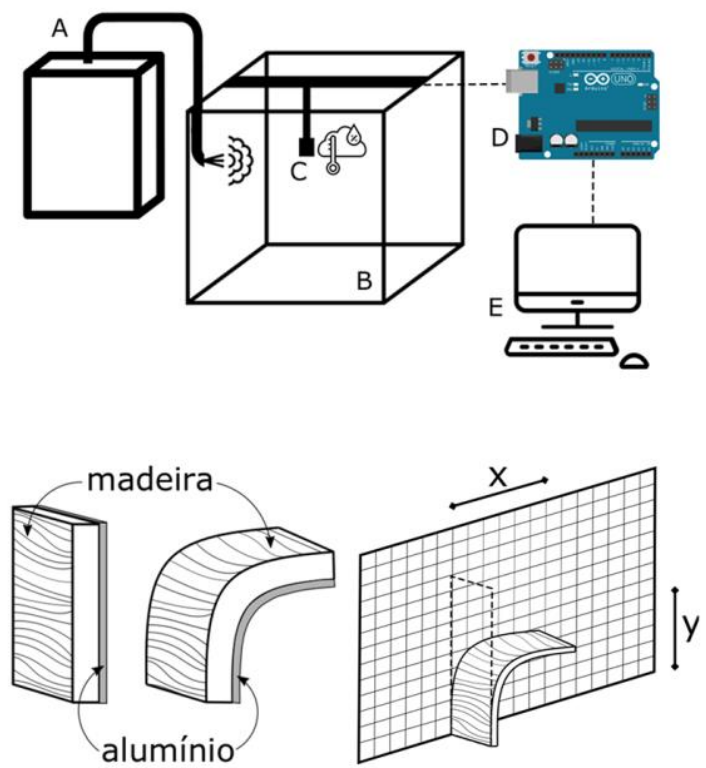

Figura 1: Imagem superior, esquema de montagem do ambiente controlado; imagem inferior esquerda, esquema de curvatura dos componentes de madeira e alumínio (espessuras aumentadas para fins ilustrativos); imagem inferior direita, esquema de medição das curvaturas conforme a passagem do tempo: em tracejado a posição inicial, em linha cheia a representação da curvatura com o aumento da umidade e a passagem do tempo. 
Os testes foram realizados dentro de um ambiente controlado (Figura 2). Uma fonte de vapor de água (A) libera vapor dentro de uma caixa de vidro vedada (B), com um sensor de umidade e temperatura (C) para registro dos dados ambientais. O sensor está conectado a uma placa Arduino (D), que envia as informações a um computador (E), onde os dados são armazenados para comparação com os registros fotográficos e em vídeos timelapse da evolução das deformações.

Um papel milimetrado colado externamente em uma das faces da caixa vedada serviu de base para as medições das curvaturas das deformações (Figura 2). As amostras eram fotografas no início e no final dos testes, dentro da caixa, já posicionadas no suporte, e as imagens registradas foram posteriormente processadas em um editor de imagens, para corrigir as distorções causadas pela lente da câmera e para fazer as comparações entre as posições inicial e final de cada amostra, e determinar a intensidade das deformações ocorridas, relacionando com os dados de mudança de umidade e temperatura obtidos por meio do sensor.

As amostras eram colocadas na caixa vedada, o registro dos dados ambientais era começado, as fotografias iniciais eram feitas, o vídeo timelapse era iniciado, e então era aplicado vapor ao ambiente até que o sensor acusasse umidade relativa de $99,9 \%$, quando a fonte de vapor era desligada, mas a caixa permanecia vedada por mais trinta minutos, enquanto as amostras passavam por deformações pelo aumento da umidade. Terminados os trinta minutos, o vídeo era encerrado, novas fotografias eram feitas e a caixa vedada era aberta para a retirada das amostras, que eram então deixadas em uma superfície plana, fora do ambiente da caixa vedada, e cronometrado o tempo necessário para o seu retorno ao formato inicial (Tabela 1).

Tabela 1: Curvaturas das amostras no início $(x 0, y 0)$ e no final ( $x 30$ ', y30') dos testes, e tempo de retorno ao formato original.

\begin{tabular}{|c|c|c|c|c|c|c|c|c|}
\hline \multirow{2}{*}{\multicolumn{2}{|c|}{$\begin{array}{cc}\text { Espéci } & \text { x0 } \\
\mathrm{e} & (\mathrm{e} \\
& \mathrm{m} \\
& \mathrm{cm}) \\
& \text { Angelim-pec }\end{array}$}} & \multirow{2}{*}{$\begin{array}{l}\mathrm{y} 0 \\
(\mathrm{em} \\
\mathrm{cm}) \\
\mathrm{a}\end{array}$} & \multirow{2}{*}{$\begin{array}{l}\times 30 \\
(\mathrm{em} \\
\mathrm{cm}) \\
\end{array}$} & \multirow{2}{*}{$\begin{array}{l}\text { y30' } \\
(\mathrm{em} \\
\mathrm{cm}) \\
0\end{array}$} & \multicolumn{4}{|c|}{$\begin{array}{c}\text { Tempo de retorno (em } \\
\text { min) }\end{array}$} \\
\hline & & & & & 11,5 & 3,5 & 11,0 & $>60$ \\
\hline \multicolumn{3}{|c|}{ Cumaru } & \multicolumn{2}{|c|}{1,0} & 12,5 & 5,0 & 11,5 & 40 \\
\hline \multicolumn{3}{|c|}{ Curupixá } & \multicolumn{2}{|c|}{1,0} & 11,5 & 11,0 & 5,5 & $>60$ \\
\hline \multicolumn{3}{|c|}{ Garapeira } & \multicolumn{2}{|c|}{1,0} & 12,5 & 7,5 & 8,5 & $>60$ \\
\hline \multicolumn{3}{|c|}{ Muiracatiara } & \multicolumn{2}{|c|}{2,0} & 12,5 & 9,0 & 8,5 & 40 \\
\hline \multicolumn{3}{|c|}{ Tauari } & & 1,0 & 11,5 & 8,5 & 4,5 & $>60$ \\
\hline
\end{tabular}

Entre as seis espécies testadas, duas se destacaram como tendo melhor resposta para curvatura: cumaru e muiracatiara. As madeiras foram observadas por uma hora para análise do retorno; dentro deste período, apenas a muiracatiara e a cumaru retornaram, em 40 minutos, as outras tiveram tempo superior e foram descartadas. Foram repetidos os testes com a camada passiva em alumínio com as duas espécies que apresentaram melhor resultado, como mostra a Figura 3. A muiracatiara foi selecionada para ser usada nos testes seguintes, uma vez que apresentou menor tempo de
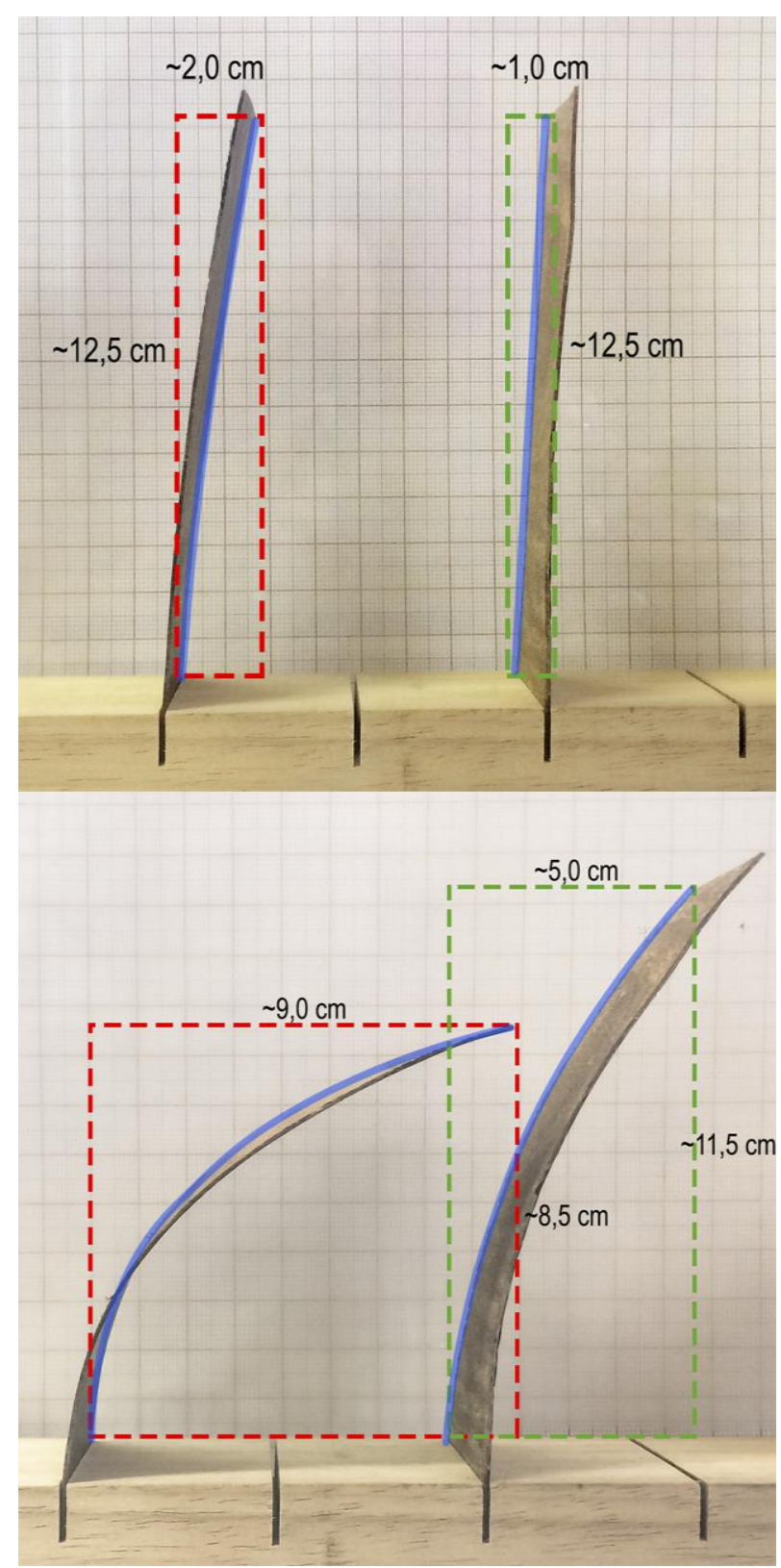

Figura 3: Componentes de dupla camada de lâminas de muiracatiara (tracejado vermelho) e cumaru (tracejado verde) com alumínio para fotografia. Acima, no início dos testes; abaixo, no final, com deformações causadas pelo aumento da umidade.

retorno à sua forma original, a muiracatiara levou 39 minutos, e a cumaru, 41 minutos.

\section{ETAPA 2 - OFICINAS SOBRE ARQUITETURA PERFORMATIVA E MATERIAIS RESPONSIVOS}

As oficinas foram realizadas em duas tardes, com duas turmas diferentes, para alunos da graduação de diversas fases do curso de Arquitetura e Urbanismo. As turmas continham dez e oito alunos respectivamente, e tiveram a duração de cerca de quatro horas. A estrutura de ambas foi similar, com uma breve aula teórica inicial sobre Arquitetura Performativa, Materiais Responsivos e Materiais Responsivos de Madeira, em que foram apresentados os conceitos e exemplos dos temas. A seguir, os participantes foram convidados a desenvolver seus próprios desenhos, por meio de ferramenta CAD, para confecção de um protótipo higroscopicamente responsivo de dupla camada de madeira e alumínio. Os desenhos foram enviados para a cortadora a laser, que 
acelerou a etapa de corte da lâmina de madeira de muiracatiara, além de permitir maior liberdade de formas dos modelos, o que não seria possível se esta etapa fosse realizada manualmente. A lâmina de madeira é difícil de ser cortada com ferramentas manuais por se quebrar facilmente ao longo das fibras e por ser rígida. Esses problemas foram contornados com a cortadora a laser, embora algumas peças com partes muito pequenas no sentido paralelo às fibras ainda tenham se quebrado, devido à fragilidade da lâmina de madeira.

Com a madeira cortada, os alunos cortaram à mão a folha de alumínio que serve de camada passiva nos componentes. As camadas foram unidas com o uso de cola de contato, aplicada nas faces em contato das duas camadas, que então foram unidas e pressionadas. Devido à duração das oficinas, o tempo total de cura da cola não foi respeitado, e depois de cerca de trinta minutos de espera, os protótipos foram testados no ambiente controlado da caixa vedada (Figura 4).

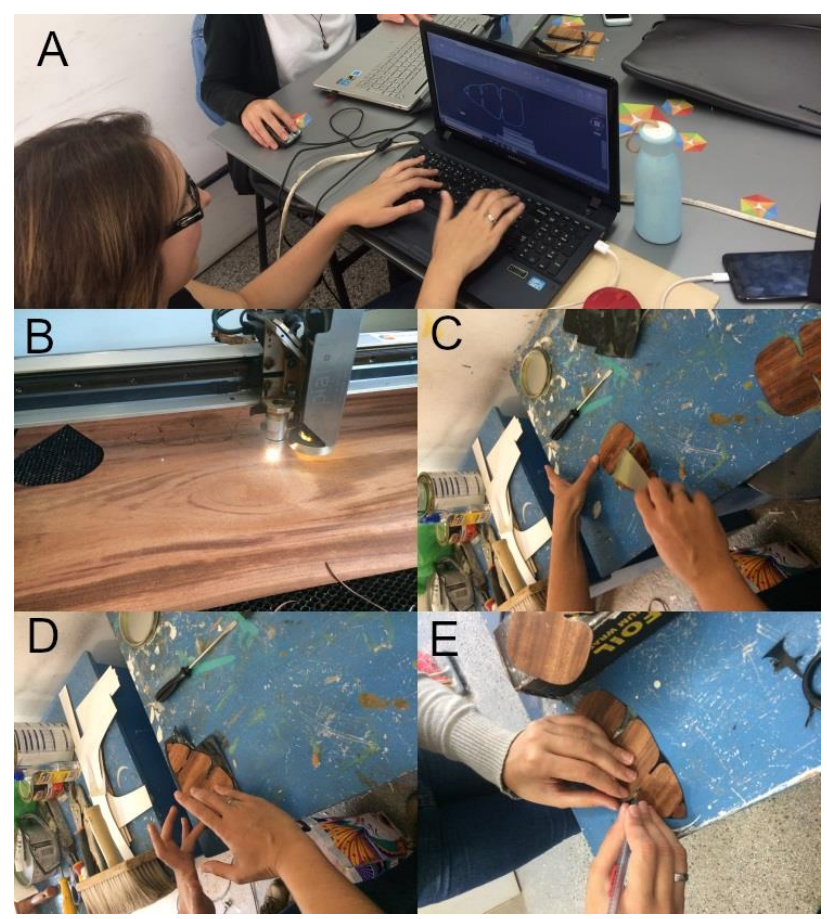

Figura 4: Etapas de montagem dos protótipos na oficina. (A) Desenho com auxílio de ferramenta CAD; (B) Corte a laser da lâmina de muiracatiara; (C) Camada de cola na lâmina; (D) União da madeira com o alumínio; (E) Recorte do excedente do alumínio. Fonte: autores.

$\mathrm{Na}$ primeira oficina, foram testados todos os vinte protótipos desenvolvidos, em quatro rodadas de testes. Três componentes não apresentaram resposta esperada devido à orientação das fibras não estar favorável - o sentido das fibras era perpendicular ao eixo transversal das peças - ou pelas dimensões apresentadas estruturas com dimensões semelhantes tendem a apresentar menor resposta do que aquelas com formatos mais alongados (Reichert et al., 2015). Com esses resultados, foi dada maior ênfase a esses pontos na oficina seguinte, para que todos os próximos protótipos fabricados apresentassem resposta satisfatória. Já na segunda oficina, foram produzidos oito protótipos (Figura 5), mas por conta de atrasos na etapa do corte a laser, não foi possível submeter ao teste todos os protótipos no mesmo dia. Foram testados cinco protótipos em duas
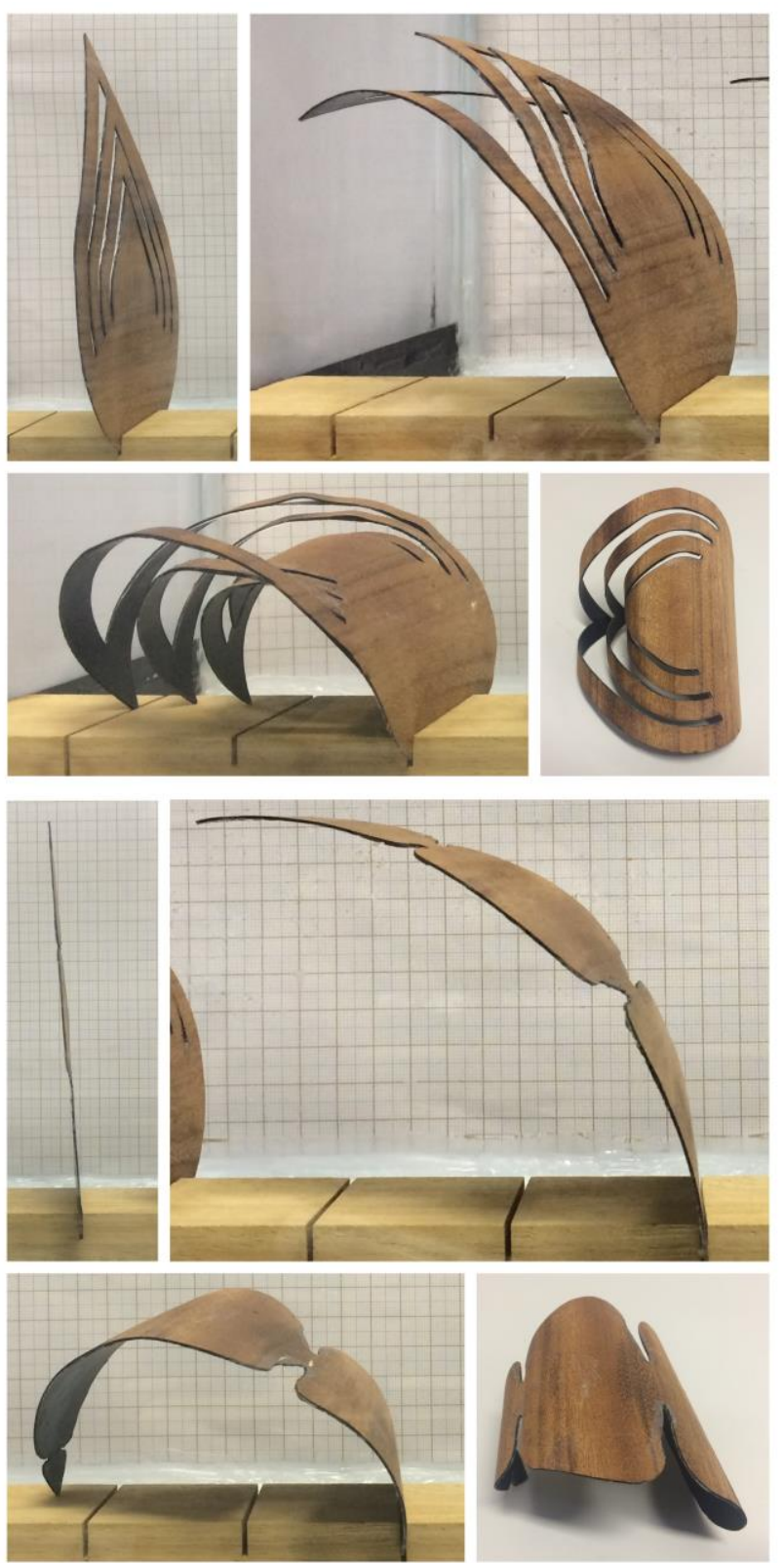

5

Figura 5: Dois protótipos produzidos pelos participantes durantes as oficinas e suas alterações conforme mudança da umidade. Fonte: autores.

rodadas, e todos responderam à variação de umidade dentro do ambiente controlado.

\section{AVALIAÇÃO DOS RESULTADOS}

Para a primeira oficina, a análise dos resultados foi feita com o uso de dados qualitativos, pela construção do discurso do sujeito coletivo, com as opiniões expressas pelos participantes ao final da oficina. Para a segunda oficina, a análise foi feita através de dados quantitativos e qualitativos, obtidos por um questionário estruturado fechado fornecido aos participantes ao final da oficina (Richardson \& Peres, 1999).

$\mathrm{Na}$ primeira oficina, os estudantes demonstraram interesse com os temas apresentados, que são inovadores e incomuns de serem abordados nas salas de aula. A ligação com outros temas, como eficiência energética, arquitetura bioclimática e sustentabilidade, também foi mencionada, embora tenha surgido a 
preocupação com os custos de manutenção de sistemas de materiais responsivos e se isso ainda pode ser um impedimento para o uso desses materiais em certos casos da arquitetura. Duas pessoas se mostraram interessadas na pesquisa com materiais responsivos com madeira, e dispostas a incorporá-los em seus projetos das disciplinas da graduação.

Para a turma seguinte, elaborou-se um questionário com o intuito de levantar as dificuldades dos alunos durante a segunda oficina, quais os tópicos considerados de maior relevância e como aprimorar a oficina. Foram obtidas sete respostas dos oito participantes presentes. A estrutura do questionário buscava, de início, traçar o perfil básico dos integrantes, em relação a que fase do curso de arquitetura se encontram e se tinham algum conhecimento prévio sobre os temas tratados na oficina. Grande parte dos estudantes se encontravam no último ano do curso $-71 \%$ na $8^{\underline{a}}$ ou $9^{\text {a }}$ fase do curso, enquanto $29 \%$ na $4^{a}$ e $5^{\text {a }}$ fase da graduação. Sobre conhecimentos prévios, $43 \%$ dos alunos declararam não ter conhecimentos sobre os assuntos, $29 \%$ afirmaram ter algum entendimento sobre arquitetura performativa, apenas um afirmou conhecer materiais responsivos, e uma pessoa afirmou ter conhecimento tanto sobre arquitetura performativa quanto sobre materiais responsivos. Os indivíduos que afirmaram ter algum conhecimento sobre os assuntos da oficina estavam nas fases mais adiantadas do curso.

As perguntas seguintes tratavam sobre as dificuldades encontradas pelos alunos durante a oficina. Em relação ao conteúdo teórico, todos responderam ter sido de fácil ou muito fácil entendimento. Na parte prática, $43 \%$ não manifestaram problemas na elaboração do protótipo, e o restante apontou como único obstáculo a falta de inspiração para desenhar os protótipos, sendo que não apresentaram dúvidas no uso dos softwares ou nas instruções recebidas sobre o funcionamento do sistema de dupla camada de madeira e alumínio. Sobre dificuldades na etapa manual da confecção dos protótipos - corte do alumínio, colagem das camadas, montagem dos protótipos -, todos responderam não ter tido problemas.

O tempo disponibilizado para as atividades da oficina foi considerado suficiente para $57 \%$ dos convidados, e a proporção entre parte teórica e prática foi considerada adequada também por $57 \%$, embora $29 \%$ tenha afirmado sentir necessidade de mais tempo de explicação teórica, e $14 \%$ assinalou mais tempo para parte prática. O atraso na etapa do corte a laser pode ter motivado as respostas que pediram por mais tempo de prática e que afirmaram não ter sido suficiente o tempo disponível para a oficina.

Três questões buscaram dados sobre a importância e relevância dos temas tratados durante a oficina. Os alunos foram questionados sobre a relevância do conhecimento adquirido em sua formação e $71 \%$ considerou o saber relevante, $14 \%$ muito relevante, e outros 14\%, irrelevante. Em referência à probabilidade de aplicação futura do conhecimento aprendido, 57\% respondeu ser provável, 14\% improvável e $29 \%$ indiferentes. Essas respostas estão de acordo com a observação realizada, na qual diversos participantes manifestaram suas dúvidas com relação à aplicação dessa tecnologia, quanto à durabilidade e manutenção, ao mesmo tempo em que acreditam que ainda não será facilmente aplicada a curto prazo.

Quando indagados se acreditavam que o conteúdo abordado na oficina poderia ser incorporado ao ensino de arquitetura, todos os integrantes do curso responderam que sim. Isso demonstra que há interesse por parte dos alunos em temas contemporâneos da arquitetura, ainda que não sejam abordados em sala de aula.

Em questão aberta foi perguntado sugestões e contribuições para a oficina. Sobre a parte teórica da oficina, um participante sugeriu aprofundar mais a teoria e outro pediu mais exemplos de arquitetura responsiva com madeira e aplicações que estejam vinculadas ao conforto ambiental. Essa opinião está de acordo com as observações feitas durante as oficinas, em que os estudantes questionaram sobre como os materiais responsivos podem contribuir para melhorar o conforto ambiental das edificações, e quais materiais podem ser usados nesse propósito.

Quanto à parte prática da oficina, uma pessoa sugeriu realizar os testes a partir de um projeto já elaborado - o que condiz com os $57 \%$ que apontaram como dificuldade na elaboração dos protótipos a inspiração para desenhar. Também foi proposta maior dinâmica na parte prática da oficina, provavelmente por conta do tempo de espera na etapa de corte das lâminas de madeira. Sobre a escala dos protótipos trabalhados, foi sugerida uma escala maior de trabalho, o que facilitaria a visualização dos efeitos de resposta dos protótipos, enquanto outro membro do grupo salientou que uma escala menor reduziria o tempo de espera do corte a laser. Todas essas opiniões concordam com a declaração dos $43 \%$ que disseram ser insuficiente o tempo da oficina. Uma pessoa propôs a introdução da oficina como parte de uma disciplina de projeto arquitetônico.

\section{DISCUSSÃO}

Com os resultados obtidos, a experiência inicial com as duas turmas nas oficinas demonstrou que é possível passar os conceitos básicos de arquitetura performativa e materiais responsivos em um curto período, com equipamentos e materiais de baixo custo. Para o espaço disponível, o número de participantes nas turmas estava dentro dos limites, a possibilidade de ampliar a quantidade de pessoas orientando em um espaço maior, pode aumentar o limite máximo de participantes. Apesar das afirmações em relação à falta de inspiração para o desenho dos protótipos, os alunos tentaram adaptar alguns dos exemplos mostrados, ou pela forma, ou pelo modo de funcionamento, o que rendeu protótipos com resultados interessantes (Figura 5), que buscavam explorar as possibilidades de abertura e fechamento dos exemplos e podem ser estudados em pesquisas futuras. A primeira oficina orientou a aplicação da segunda, e isso se refletiu na execução técnica aperfeiçoada dos protótipos, em que todos apresentaram resposta, e com mais experimentos com as curvaturas e aberturas dos componentes, variando as faces das camadas ativas e passivas, além do desenvolvimento e aplicação do questionário, para coleta de dados.

Os materiais e as ferramentas usadas foram adequados, não sendo necessário nenhum material extra. O único 
entrave foi o atraso provocado pela cortadora a laser, que não estava adequada, não possibilitando todos os testes no mesmo dia da segunda oficina. A Figura 6 a seguir apresenta um resumo esquematizado das atividades e equipamentos utilizados na oficina.

Para futuras pesquisas, pode-se considerar uma oficina de maior duração, de dia inteiro, e, com base nos resultados, ampliar as discussões teóricas para temas

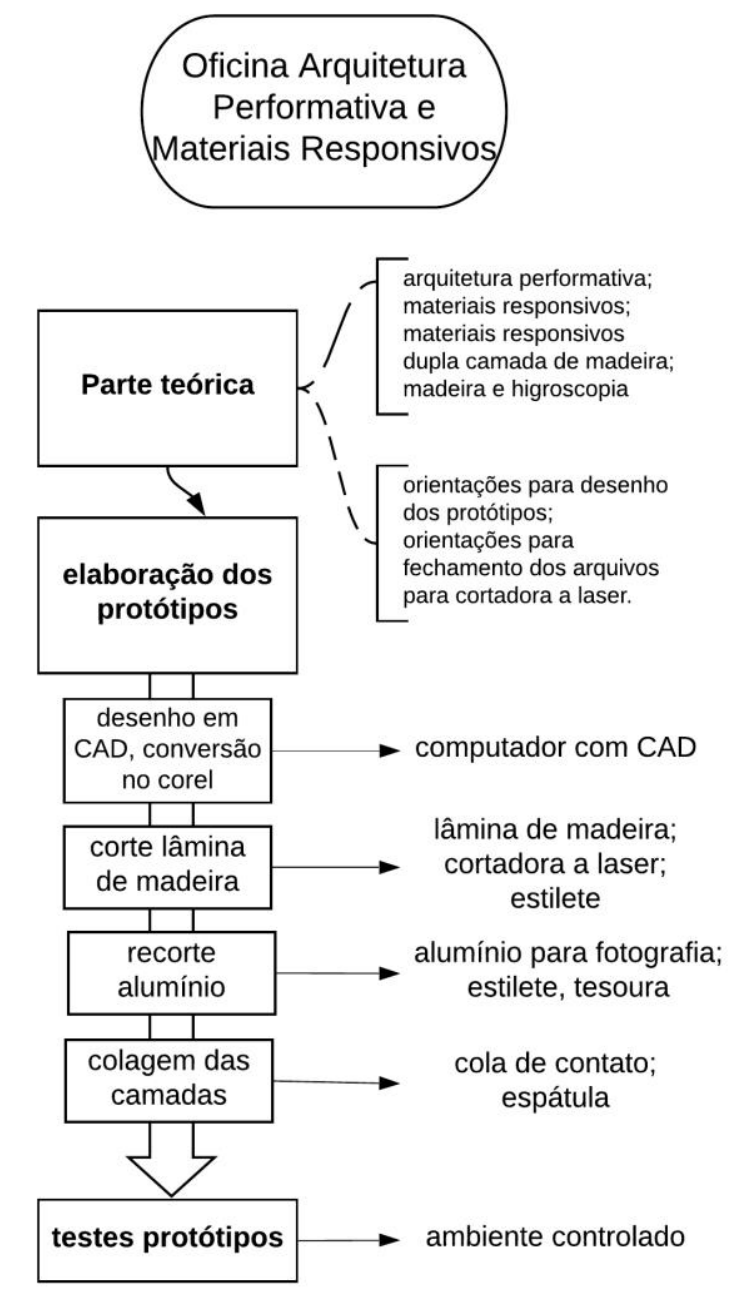

Figura 6: Esquema resumo da oficina. Fonte: autores.

como conforto ambiental, durabilidade dos componentes e maior enfoque em materiais higroscopicamente responsivos de dupla camada de madeira. É uma atividade fácil de implementar, de baixo custo, se houver a possibilidade de uso de uma cortadora a laser a etapa de corte da lâmina é mais rápida e simples, mas é possível que esta etapa seja feita de modo manual. Os outros equipamentos são acessíveis, e os alunos se mostraram animados com os temas e com os resultados.

\section{AGRADECIMENTOS}

Agradecemos à CAPES pelo financiamento desta pesquisa, e ao laboratório Pronto 3D UFSC por ceder o espaço.

\section{REFERÊNCIAS}

Addington, D. M., \& Schodek, D. L. (2005). Smart materials and new technologies : for the architecture and design professions. Amsterdam ; London: Elsevier.

Hensel, M. U. (2011). Performance-oriented Architecture and the Spatial and Material Organisation Complex. Rethinking the Definition, Role and Performative Capacity of the Spatial and Material Boundaries of the Built Environment. Formakademisk, 4(1), 3-23. doi:http://dx.doi.org/10.7577/formakademisk.125

Holstov, A., Bridgens, B., \& Farmer, G. (2015). Hygromorphic materials for sustainable responsive architecture. Construction And Building Materials, 98, 570-582. doi:http://dx.doi.org/10.1016/j.conbuildmat.2015.08.136

Kolarevic, B., \& Malkawi, A. (2005). Performative architecture : beyond instrumentality. London: Spon Press.

Lenz, D., \& Celani, G. (2015). Performative architecture: Uma arqueologia tecnológica. Arquitextos, (186.04).

http://vitruvius.com.br/revistas/read/arquitextos/16.186/5844

Menges, A., \& Reichert, S. (2015). Performative Wood Physically Programming the Responsive Architecture of the HygroScope and HygroSkin Projects. Architectural Design, 85(5), 66-73. doi:10.1002/ad.1956

Nahuz, M. A. R. (Ed.) (2013). Catálogo de madeiras brasileiras para a construção civil São Paulo - SP: Instituto de Pesquisas Tecnológicas do Estado de São Paulo - IPT.

Reichert, S., Menges, A., \& Correa, D. (2015). Meteorosensitive architecture: Biomimetic building skins based on materially embedded and hygroscopically enabled responsiveness. Computer-aided Design, 60, 50-69. doi:http://dx.doi.org/10.1016/j.cad.2014.02.010

Richardson, R. J., \& Peres, J. A. d. S. (1999?). Pesquisa social: métodos e técnicas (3 ed.). São Paulo: Atlas.

Skaar, C. (1988). Wood-water relations. Berlin: Springer.

Walker, J. C. F. (2006). Primary wood processing : principles and practice (2 ed.). Dordrecht, The Netherlands: Springer. 